\title{
PMU-Assisted Overcurrent Protection for Distribution Feeders Employing Solid State Transformers
}

\author{
H. Hooshyar, Member, IEEE, M. E. Baran, Fellow, IEEE, S. R. Firouzi, Student Member, IEEE, and \\ L. Vanfretti, Senior Member, IEEE
}

\begin{abstract}
Solid State Transformer (SST) has recently emerged as an approach to facilitate the integration of Distributed Energy Resources (DERs) at the distribution system level. However, SSTs impact the operation and coordination of protection relays as they will contribute to the fault current during a fault. This paper shows that the impact of SSTs on the overcurrent protection relays can be considerable. The paper proposes an enhancement to the traditional overcurrent scheme by exploiting embedded PMU functionality in SSTs and in feeder protective relays. Performance of the proposed scheme has been assessed through the use of hardware-in-the-loop simulation on a sample distribution feeder.
\end{abstract}

Index Terms-- distribution system, overcurrent protection, PMU, solid state transformer (SST).

\section{INTRODUCTION}

\section{A. Motivation}

Overcurrent protection has been traditionally the primary scheme employed for protection of distribution feeders. This is mainly due to its simplicity of operation and low maintenance costs [1].

Recently, there has been considerable effort towards infusion of new technologies into distribution systems in order to facilitate the integration of Distributed Energy Resources (DERs) into a distribution system [2-3]. Microgrids have emerged as one of the approaches [4], and an extended version of this approach employs power electronics based Solid State Transformer (SST) to replace the magnetic distribution transformer at every node to facilitate DER integration [5]. SST offers very desirable features such as regulated voltage at the secondary side, reactive power compensation at the primary side, voltage sag ride-through, and fault isolation between the primary and the secondary sides [6-8]. These features coupled with communication capabilities facilitate the management of generation, storage,

This work was supported in part by ERC Program of the National Science Foundation in US under Award Number EEC-08212121, the FP7 IDE4L project funded by the European Commission, and the STandUp for Energy Collaboration Initiative in Sweden.

H. Hooshyar, S. R. Firouzi, and L. Vanftretti are with the KTH Royal Institute of Technology, Stockholm 11428 Sweden (e-mail: \{hosseinh,srfi,luigiv\}@kth.se).

M. E. Baran is with the North Carolina State University, Raleigh, NC 27606 USA (e-mail: baran @ ncsu.edu). and loads at the distribution level [9].

As SST acts as an active component in the distribution system, after a fault occurrence it remains connected to the feeder and contributes to the fault current until its selfprotection trips. SSTs that serve a balanced combination of generation and load or those that are remote to the fault location remain connected to the feeder for a relatively long time before their self-protection trips [10]. Hence, SSTs impact feeder overcurrent protection as they will contribute to the fault current during a fault, which will in turn impact the operation and coordination of protection relays considerably [11]. As illustrated in [10], SST response during a fault is more complex and quite different from that of an inverterinterfaced DG (Distributed Generator). In addition, the special self-protection scheme employed for the SST makes the current contribution from a SST different than that of a regular converter [10].

Recently, there has been growing interest and research towards adoption of Phasor Measurement Units (PMU) at the distribution system level [12-17]. This has been prompted by an ongoing and rapid evolution of distribution systems from passive to active networks. PMUs make it possible to observe system's response at the same point of time from different locations by providing real-time synchronized phasor measurements, i.e. synchrophasors [18].

\section{B. Previous Work}

Although SST has been exploited in several fields such as traction systems (for feeding the motive electrical motors) [19-21] and renewable energy power plants (for interfacing the plants with the power grid) $[22,23]$, its application at the distribution level is relatively new. Therefore, investigation of SST's impact on protection system of distribution grids and proposing protection schemes, handling this impact, has been limited in literature to special distribution systems, mainly FREEDM systems [24]. [24] and [25] suggest the application of a wide area differential protection scheme for SSTpenetrated distribution systems. The proposed scheme requires receiving a high number of 250 samples of data per cycle from each SST, making the communication infrastructure heavily loaded. In addition, it does not perform any coordination with the fuses, protecting the laterals. An alternative protection scheme is proposed in [26] and [27] in which the fault location is identified through analysis of the 
power flow in the feeders. Although the proposed scheme does not heavily rely on the communication infrastructure, it is designed for distribution systems with a loop configuration. In addition, similar to the previous scheme, it is not coordinated with the fuses.

\section{Paper Contributions}

This paper shows the impact of SSTs on the performance of overcurrent protection relays which are widely utilized in distribution systems.

The paper then proposes a scheme that enhances the traditional overcurrent scheme by exploiting embedded PMU functionality in SSTs and in feeder protective relays. The proposed scheme makes it possible for the relays to operate properly with their original reach and speed, and also stay coordinated with each other.

The proposed scheme utilizes the ICT (Information and Communication Technology) backbone, preliminarily employed for control of SSTs [28]. In addition, as the proposed scheme is an enhancement to the traditional overcurrent scheme, it allows to utilize the in-use protective hardware (relays and fuses), which makes it economically preferable over the deployment of an entirely different protection scheme.

The paper begins by an explanation on SST's structure and its impact on the fault current profile, relay trip time, and relay coordination in Section II. In Section III, the proposed overcurrent scheme together with a backup scheme are introduced. In addition, the section describes the requirements that the proposed scheme imposes on the ICT infrastructure. Conclusions are drawn in Section IV.

\section{IMPACT OF SSTS ON OVERCURRENT PROTECTION SCHEME}

This section introduces SST's structure and discusses its impact on the performance of the overcurrent relays.

\section{A. Basic Structure of SST}

The solid state transformer is a power electronic device that replaces the conventional magnetic power transformer by means of high power converters, as shown in Fig .1. The SST consists of three main components: a high voltage AC/DC rectifier that regulates a high voltage DC bus (HVDC), an isolated high frequency operated DC/DC converter to regulate the secondary DC bus (LVDC), and a DC/AC inverter to regulate the output terminal AC voltage (LVAC) which serves the local loads and DGs (alternatively called prosumer ${ }^{1}$ cluster in this paper) $[5,29]$. SST has also self-protection for which it usually employs an under/over voltage scheme that monitors the high voltage DC bus [10]. The self-protection system immediately shuts down the SST if it detects any abnormal voltages on the high voltage DC bus.

Note that there are also other topologies to implement the SST that only have one conversion stage; however, the topology shown in Fig. 1 is the most common one that is proposed to realize a SST for distribution systems [30,31].

\footnotetext{
${ }^{1}$ prosumer $=$ producer + consumer
}

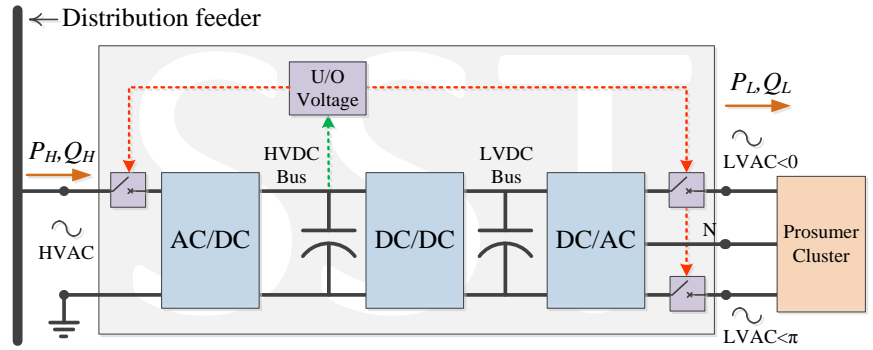

Fig. 1. Basic configuration of SST.

\section{B. Impact on Fault Current Profile}

SST acts as an active component during a fault and contributes to the fault current. This is mainly because SST regulates the $\mathrm{AC}$ voltage on the prosumer side even under low feeder voltage conditions which occur during a fault. Hence, the prosumer cluster can stay connected and contribute to the fault current through the SST, which would not have happened if the prosumer cluster was served by a conventional magnetic transformer. During this period, the SST rectifier tries to transfer the prosumer power (that can be either generative or demanding) to the distribution feeder in order to keep the HVDC bus voltage regulated. However, if the SST's primary side current gets to be higher than the maximum current rating of the SST rectifier, the rectifier limits the current at its maximum level which is typically 1 to 2 times the rated current [29].

Nevertheless, this contribution is normally limited in time by the SST's self-protection system [10,32]. As discussed in [10], the following factors affect the self-trip time of a SST: 1) the balance of prosumer load/generation that the SST serves, 2) the reactive power compensation that the SST provides to the grid, 3) post-fault voltage at the SST's terminal.

It is worth noting that SST response during a fault is more complex and quite different from that of an inverter-interfaced DG. This is mainly due to the SST's self-protection scheme, explained in the previous section, which is different from that of a DG. DGs at the low-voltage distribution level are often protected with terminal under/over frequency/voltage protection schemes against faults occurring on the distribution feeder [33]. Subsequently, the fault current contribution of DGs is restricted within a short period of time (e.g. a few cycles). Whereas SST stays connected to the feeder and contributes to the fault current for a relatively long time, as long as its HVDC bus voltage is regulated. This can happen for SSTs with $P_{L} \approx 0$ or for those that are not located in the immediate vicinity of the fault. More details can be found in [10]. In addition, as SST regulates the AC voltage on the prosumer side, it acts like either a DG sinking power to the feeder (when the generation in higher than the demand on the prosumer side) or as an active load drawing power from the feeder (when the demand in higher than the generation on the prosumer side). The latter one impacts the feeder fault current profile quite differently than inverter-interfaced DGs.

This implicates that on a feeder with many SSTs connected along its length, the SSTs will be disconnected from the feeder at different times during a fault. As a result, the fault 
current flowing through the feeder will be varying, giving it a different profile than that of a feeder with no SST.

In order to further clarify this problem, an actual distribution system serving mostly residential loads in a suburb of Raleigh NC is considered as a benchmark in this paper. The feeder has three-phase primary with several singlephase underground cables tapped off from the main circuit to feed the customers within the same neighborhood. For this study, the model of the system, implemented in MATLAB/Simulink, was modified for its use with the OPALRT real-time simulator in order to perform time domain simulations. Because it was not practical to include all loads individually in the simulation model, the loads on the singlephase laterals, served off the main line sections, have been aggregated as one lumped load, as shown in Fig. 2 (tagged as "Ld"). Also, a Photovoltaic system (PV), adopted from a typical model available at [34], has been added to each node as DG and the distribution conventional transformers have been replaced by SSTs. The SST is simulated by adopting the model, introduced in [5], which uses average models for the converters, and includes the previously discussed selfprotection system.

The protection system, employed for the distribution feeders, consists of an overcurrent relay for the substation breaker, an overcurrent recloser at the beginning of branch 1 , and several fuses to protect the laterals.

Fig. 3 compares the phase fault current flowing through the circuit breaker, $\left|\vec{I}_{B R K}\right|$, and the ground fault current measured by the breaker relay, $3\left|\vec{I}_{B R K}^{0}\right|$, with the fault current at the fault location, $\left|\vec{I}_{f}\right|$, for a line-to-ground fault occurring at node 2 with $R_{f}=3 \Omega$. In Fig. 3(a), the fault is assumed to occur at noon time when the PVs' generation is high and the loads' consumption is low, i.e. SSTs inject active power to the distribution system. Whereas in Fig. 3(b), the fault is assumed to occur at night time when the PVs' generation is low and the loads' consumption is high, i.e. SSTs draw active power from the distribution system.

As shown in the figure, in both cases, $\left|\vec{I}_{B R K}\right|$ and $3\left|\vec{I}_{B R K}^{0}\right|$ are noticeably different from $\left|\vec{I}_{f}\right|$ due to SSTs' contribution to the fault current. Also, the current profiles are varying as a result of SSTs disconnecting at different times on the feeder.

In Fig. 3(a), $\left|\vec{I}_{B R K}\right|$ is lower than $\left|\vec{I}_{f}\right|$ which is due to high post-fault system voltage caused by SSTs' injecting power to the faulty phase. Whereas in Fig. 3(b), $\left|\vec{I}_{B R K}\right|$ is higher than $\left|\vec{I}_{f}\right|$ which is due to low post-fault system voltage caused by SSTs' drawing power from the faulty phase.

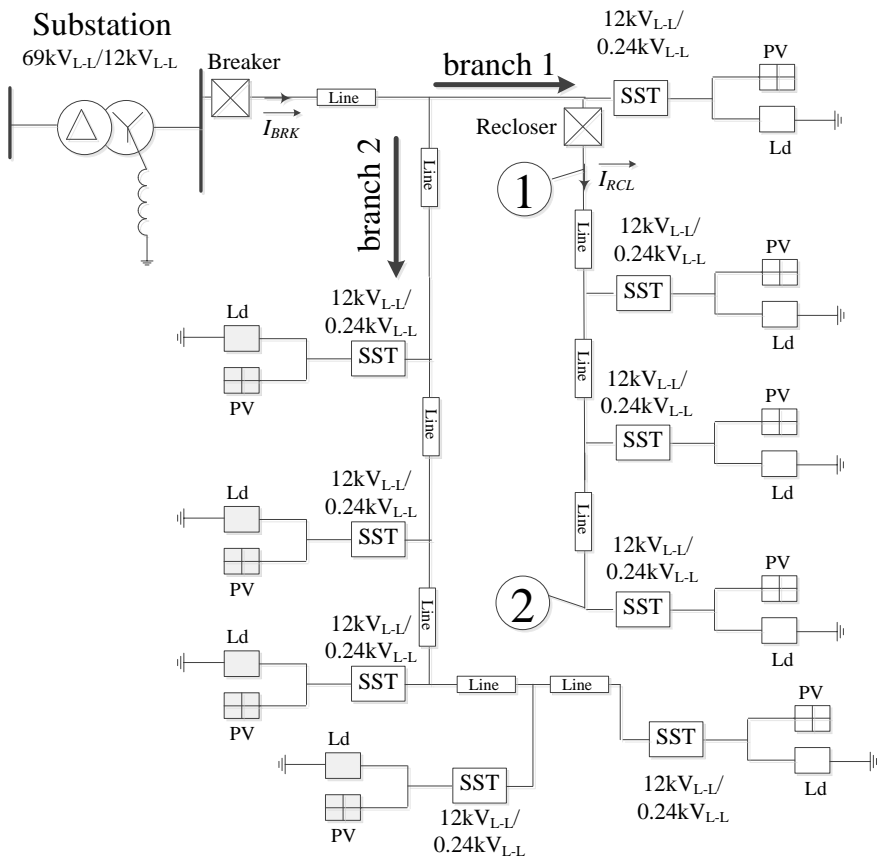

Fig. 2. A sample SST-dominated feeder (circles indicate the node numbers).

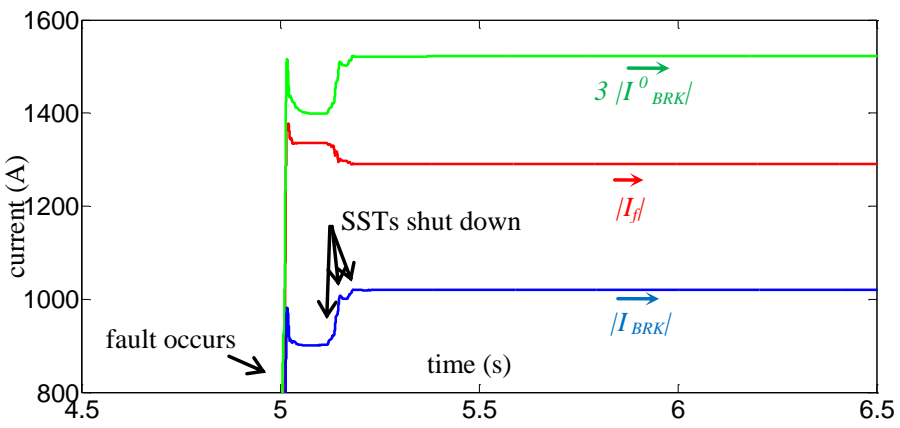

(a) Noon (SSTs inject power to the system)

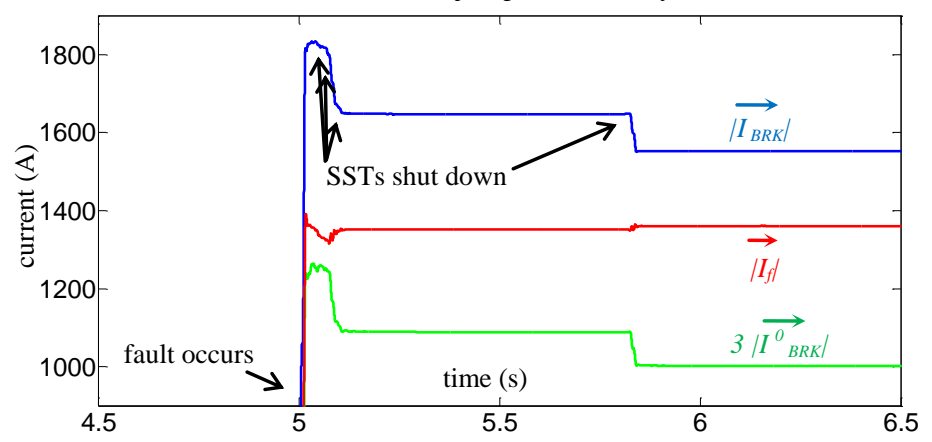

(b) Night (SSTs draw power from the system)

Fig. 3. Impact of SSTs on fault current profile of the breaker in the benchmark system. The fault is line-to-ground with $R_{f}=3 \Omega$ at node 2 .

In contrast to $\left|\vec{I}_{B R K}\right|, 3\left|\vec{I}_{B R K}^{0}\right|$ shows a different profile.

As Fig. 3 shows, it is higher than $\left|\vec{I}_{f}\right|$ at noon whereas it becomes lower than $\left|\vec{I}_{f}\right|$ at night. This difference has been further explained in Fig. 4. The figure shows the three-phase current flowing through the breaker before and after the fault occurrence at noon and at night times. As the figure shows, 
after the fault occurrence, the breaker phase ' $a$ ' current becomes equal to $\left|\vec{I}_{f}\right|$ as the SSTs on phase 'a' shut down. However, the breaker currents on phases ' $b$ ' and 'c' remain equal to $\left|\vec{I}_{S S T}^{b}\right|$ and $\left|\vec{I}_{S S T}^{c}\right|$, respectively. The measured $3\left|\vec{I}_{B R K}^{0}\right|$ is a vector sum of the breaker currents on phases 'a', 'b', and 'c'. As shown in Fig. 4, such vector sum results in $3\left|\vec{I}_{B R K}^{0}\right|$ to increase at noon time and to decrease at night time. Observe that the mentioned variations in $3\left|\vec{I}_{B R K}^{0}\right|$ becomes more severe when the self-protection of all SSTs on the faulty phase, i.e. phase 'a' in Fig. 4, shut them down after the fault occurrence.

It is worth noting that the severity of SSTs' impact on the fault currents, flowing through or measured by a relay, is proportional to the total rating of installed SSTs between that relay and the fault. For instance, the phase fault current flowing through the recloser, $\left|\vec{I}_{R C L}\right|$, and the ground fault current measured by the recloser relay, $3\left|\vec{I}_{R C L}^{0}\right|$, are impacted less than those of the breaker. As shown in Fig. 5, $\left|\vec{I}_{R C L}\right|$ and $3\left|\vec{I}_{R C L}^{0}\right|$ are relatively similar to $\left|\vec{I}_{f}\right|$. This is because for the fault occurring at node 2, all the SSTs connected to branches 1 and 2 reside between the fault and the breaker, whereas only the SSTs connected to branch 1 reside between the fault and the recloser.

It can be inferred from this test that in a SST-dominated system, the protective devices such as breaker relay, recloser, and fuse may operate inconsistently as the fault current flowing through/measured by them can be noticeably different

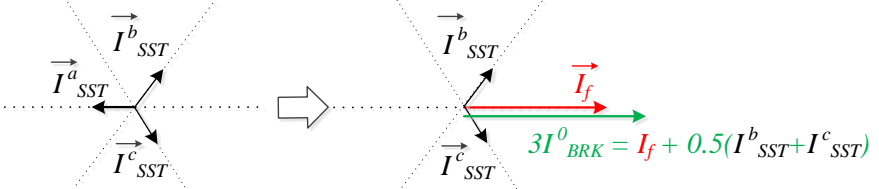

before fault

after fault (when SSTs on phase 'a' shut down)

(a) Three-phase current and ground fault current flowing through the breaker at noon (SSTs inject power to the system)

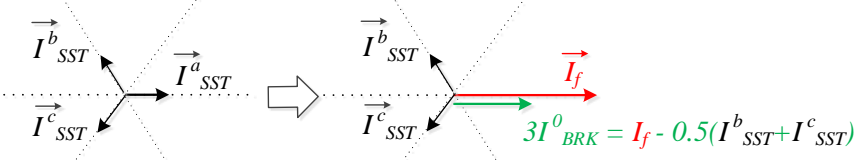

before fault

after fault (when SSTs on phase 'a' shut down)

(b) Three-phase current and ground fault current flowing through the breaker at night (SSTs draw power from the system)

Fig. 4. Impact of SSTs on the measured ground fault current for a line-toground fault occurring on phase ' $a$ '.

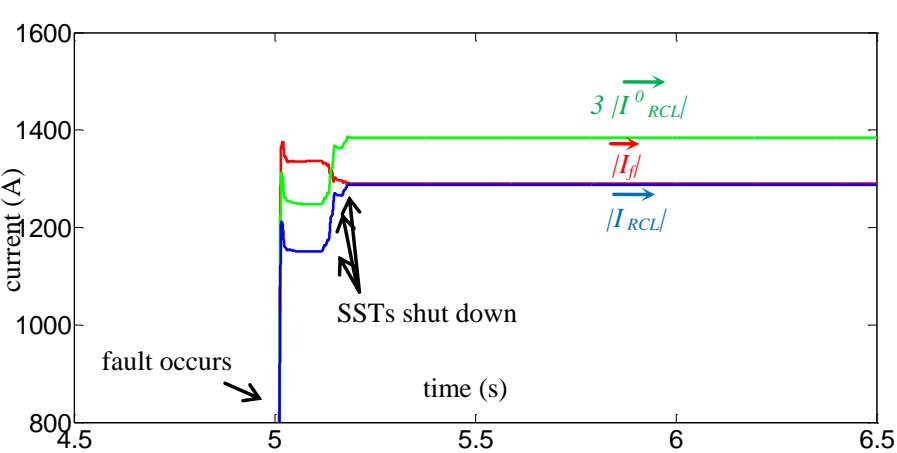

(a) Noon (SSTs inject power to the system)

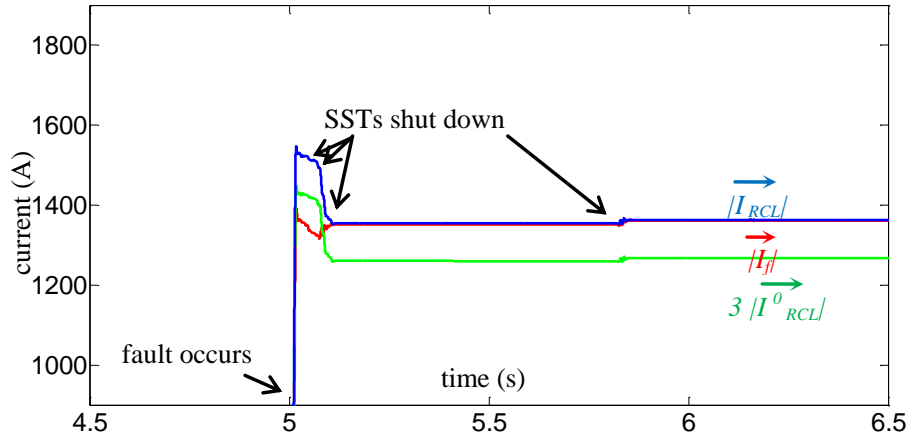

(b) Night (SSTs draw power from the system)

Fig. 5. Impact of SSTs on fault current profile of the recloser in the benchmark system. The fault is line-to-ground with $R_{f}=3 \Omega$ at node 2 .

from the fault current at the fault location. This will be further explained in the next section.

\section{Impact on Relay Trip Time}

The fault current variation and difference, discussed in the previous section, will in turn impact the operation of protective devices considerably. Fig. 6 shows the trip time variation of the breaker ground relay in the benchmark system for different load/generation balance of the local prosumers served by the SSTs. As the figure shows, the fault current contribution of SSTs impacts both speed and reach of the relay, making them noticeably different from those of the relay original design.

The impact is negligible for bolted faults; however, it becomes severe as the fault resistance increases. For bolted faults, the fault current contribution of the power grid is much higher than that of the SSTs, so SSTs' fault current contribution is relatively small. This makes the SST's impact on the relay trip time negligible.

Note that the breaker in our benchmark has three-phase operation, hence the ground relay uses $3\left|\vec{I}_{B R K}^{0}\right|$ as input to detect and trip against line-to-ground faults. If the breaker had single-phase operation, the ground relay would have used $\left|\vec{I}_{B R K}\right|$ as input which would have impacted its trip time differently.

Similar analysis could be done on the breaker phase relay. However since the three-phase and the line-to-line faults are normally bolted, it has been skipped in this section. 


\section{Impact on Coordination}

The trip time variation of the relays, discussed in the previous section, may also affect the coordination between them. Normally, in order to preserve the coordination between any two consecutive relays, a time margin is set between their trip times against the most severe fault seen by both of them, e.g. a bolted fault at node 1 for the breaker relay and the recloser of the benchmark. Fig. 7 shows the $0.1 \mathrm{~s}$ time margin set between the recloser and the breaker ground relays of the benchmark against the $I_{f m a x}$ of 2673 A. As explained in the previous section, for bolted faults, the SST's impact is negligible on the trip time of the relays; therefore, the time margin is preserved for fault currents of around $I_{\text {fmax }}$. However, for faults with resistance, the SSTs located between the two relays can cause the upstream relay to see/measure a noticeably higher fault current than that of the downstream one, as shown in Fig. 7 for the breaker ground relay at $I_{f}$ of 600 A. This difference may lead the upstream relay to violate the time margin or even to trip faster than the downstream one. This is due to the SST's impact, explained in Section II.B, which may occur at noon time for ground relays inputting the measured ground current, $3\left|\vec{I}^{0}\right|$, or at night time for

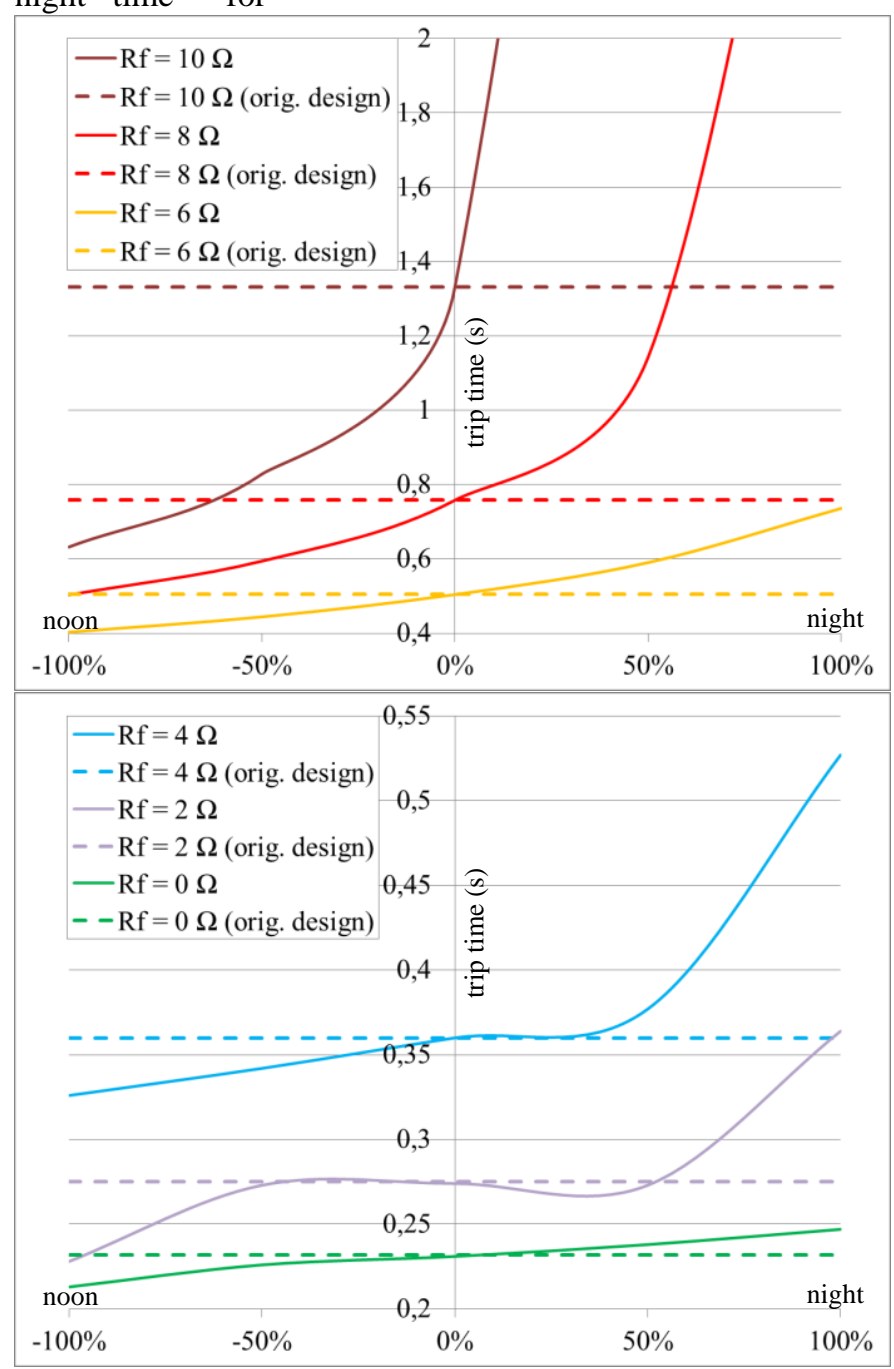

(generation-load)\% balance of prosumer clusters

Fig. 6. Impact of SSTs on trip time of the breaker ground relay in the benchmark system. The fault is line-to-ground at node 2 .

ground/phase relays inputting the phase current, $|\vec{I}|$.

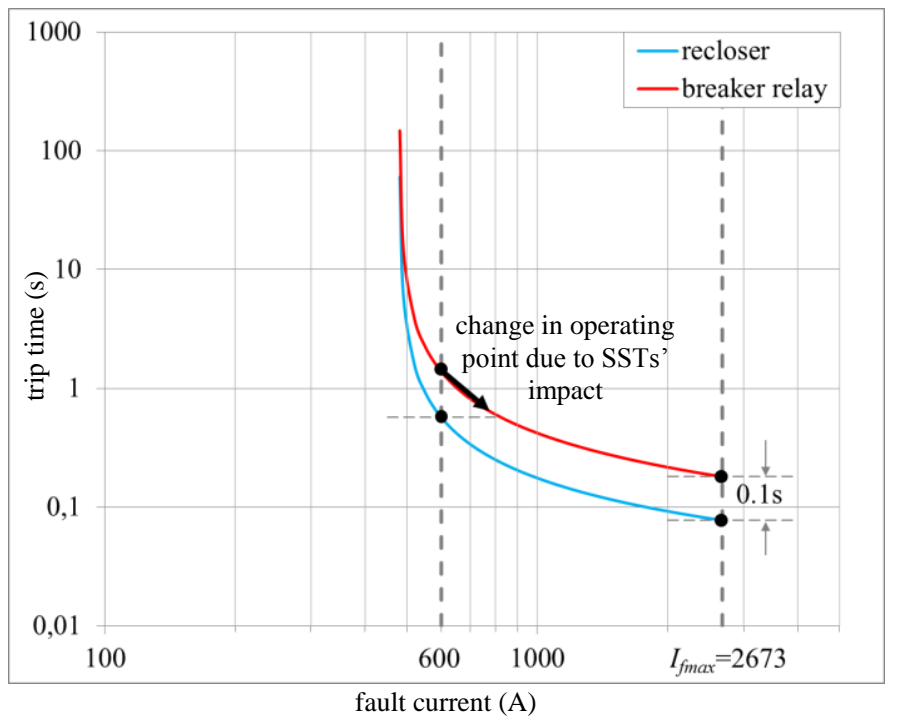

Fig. 7. Time-current curves of the ground relays of the breaker and the recloser of the benchmark system.

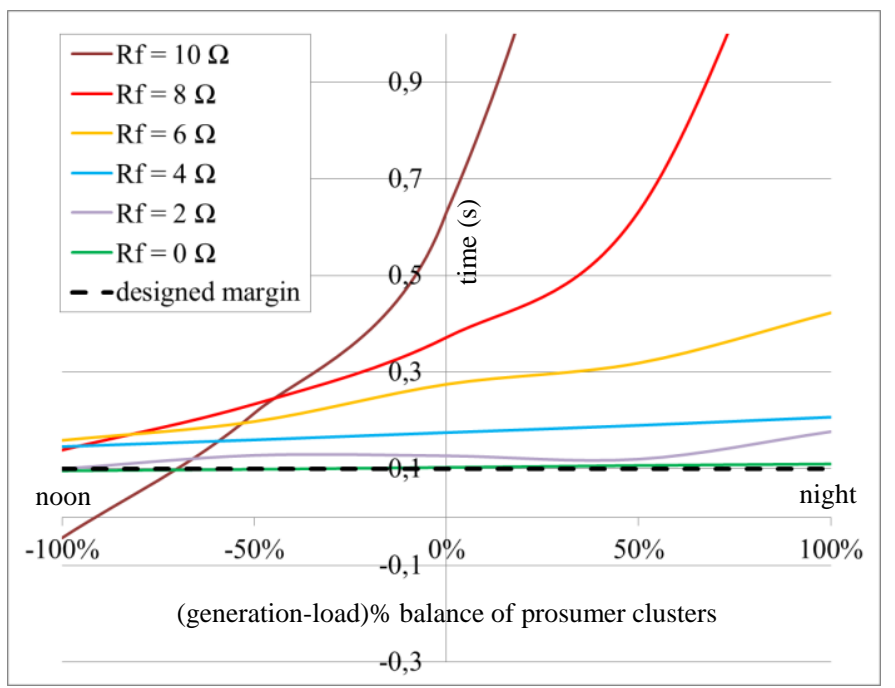

(a) fault occurs at node 1

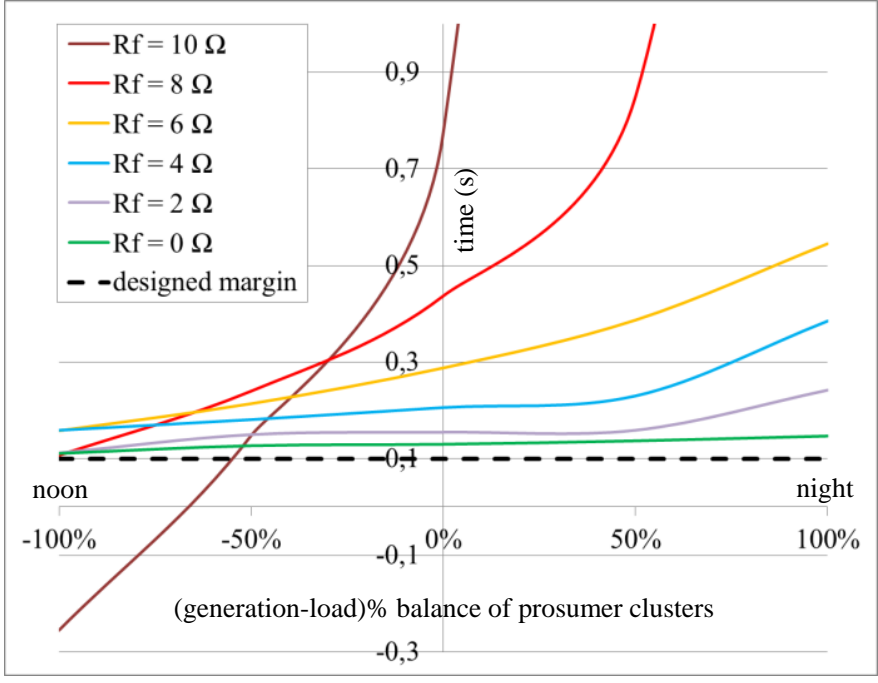

(b) fault occurs at node 2 
Fig. 8. Impact of SSTs on trip time difference between the ground relays of the breaker and the recloser of the benchmark system.

Fig. 8 shows the trip time difference between the ground relays of the breaker and the recloser of the benchmark system, i.e. breaker trip time minus recloser trip time, for different load/generation balance of the local prosumers served by the SSTs. The figure shows the results for faults occurring at node 1 and node 2 that are the beginning and the end of the recloser protection zone, respectively. As shown in the figure, for both nodes when $R_{f}=10 \Omega$, the trip time difference becomes less than the designed time margin, i.e. 0.1 $\mathrm{s}$, violating the coordination. It becomes even negative for generation/load balance of less than $-50 \%$, which means that the breaker will trip faster than the recloser. Note that this effect is more serious when the fault occurs at node 2 . This is because the fault current contribution of the power grid becomes more limited for faults occurring at the end of the feeder, due to the feeder impedance; hence, the SSTs' impact becomes more noticeable at node 2. However, observe that this is not always the case, as it also depends on the length and the impedance of the feeder as well as if the relays input the phase current or the measured ground current. Therefore, for a given feeder employing SSTs, it has to be investigated both at the beginning and at the end of the feeder to see where the most serious problem of loss of coordination occurs.

\section{PMU-Assisted OvercurRent PROTECTION SCHEME}

As explained in Section II, SSTs impact the operation and the coordination of protection relays by contributing to the fault current during a fault. In this section, an enhanced overcurrent protection scheme is proposed to manage SST's impact so that the relays operate properly with their original reach and speed, and also stay coordinated with each other.

Note that although it is possible to implement other types of protection schemes on the relays, the overcurrent scheme is retained to preserve the coordination between the relays and the fuses. In addition, the overcurrent scheme allows for using the currently in-use hardware (relays and fuses), making the scheme implementation less costly.

\section{A. Proposed Scheme}

\section{1) Basics and Breaker/Recloser Coordination}

The proposed scheme relies on the fact that, in contrast to the conventional feeders, in SST-dominated feeders the fault current at the fault location, $\left|\vec{I}_{f}\right|$, is different from the fault current flowing through or measured by the feeder breaker relay, the recloser, or fuses. This has been extensively discussed in Section II.B. Computing $\left|\vec{I}_{f}\right|$ in real-time and feeding it to the overcurrent relay (instead of $\left|\vec{I}_{B R K}\right| /\left|\vec{I}_{R C L}\right|$ or $3\left|\vec{I}_{B R K}^{0}\right| / 3\left|\vec{I}_{R C L}^{0}\right|$ ) enables the relay to operate with the originally designed speed and reach. Fig. 9 depicts the architecture of the proposed overcurrent scheme. As the figure indicates, the proposed scheme requires the SSTs and the relays to have PMU functionality. The scheme utilizes the PMU functionality, embedded in the SSTs and in the relays, to compute $\left|\vec{I}_{f}\right|$ and sends it to the relays in real-time. The PMUs stream the phasors of the phase currents, flowing through the SSTs/breaker/recloser, to the communication network over UDP/IP using the IEEE C37.118.2 protocol. Each relay has dedicated hardware that holds a real-time data mediator that receives, time-aligns and parses PMU data streams and makes them available for further real-time processing, i.e. the computation of $\left|\vec{I}_{f}\right|$ that is to be fed to the relay. For each relay, i.e. breaker relay or recloser, $\left|\vec{I}_{f}\right|$ of phase ' $a$ ' is obtained as:

$$
\left|\vec{I}_{f}^{a}\right|=\left|\vec{I}_{\text {relay }}^{a}+\sum \vec{I}_{S S T}^{a}\right|
$$

where $\vec{I}_{\text {relay }}^{a}$ can be $\vec{I}_{B R K}^{a}$ or $\vec{I}_{R C L}^{a}$, and $\vec{I}_{S S T}^{a}$ is the current of any SST connected to phase ' $a$ ' in the protection zone of the relay. Similar equations can be derived for phases ' $b$ ' and 'c'. The computed $\left|\vec{I}_{f}^{a}\right|$ is fed to the phase relay and also the ground relay if it inputs phase current. For ground relays inputting $3\left|\vec{I}^{0}\right|,\left|\vec{I}_{f}\right|$ is obtained as:

$$
\left|\vec{I}_{f}\right|=\left|\vec{I}_{f}^{a}+\vec{I}_{f}^{b}+\vec{I}_{f}^{c}\right|
$$

Feeding $\left|\vec{I}_{f}\right|$ to the recloser relay and also to the upstream breaker relay not only enables them to operate with the original speed and reach, but also helps them to preserve the coordination as they both see the actual fault current.

Note that the computation of $\left|\vec{I}_{f}\right|$ is performed per phase (i.e. $\left|\vec{I}_{f}^{a}\right|,\left|\vec{I}_{f}^{b}\right|$, and $\left|\vec{I}_{f}^{c}\right|$ ) regardless of the fault type. Hence, the proposed scheme readily protects the system against faults of any type.

\section{2) Fuse Coordination with Breaker/Recloser}

SST's impact on fuse operation is normally negligible. As explained in Section II.B, severity of SSTs' impact on the fault currents, flowing through or measured by a protective device, is proportional to the total rating of the installed SSTs between that device and the fault. Fuses are used for protection of feeder laterals each feeding few numbers of SSTs. Therefore, if a fault occurs on a lateral, there will be a relatively low installed rating of SSTs between the fuse, protecting the lateral, and the fault. Hence $\left|\vec{I}_{\text {fuse }}\right|$ will be relatively the same as $\left|\vec{I}_{f}\right|$. Since in the proposed overcurrent scheme, the recloser inputs $\left|\vec{I}_{f}\right|$, the recloserfuse coordination will not be hindered. 


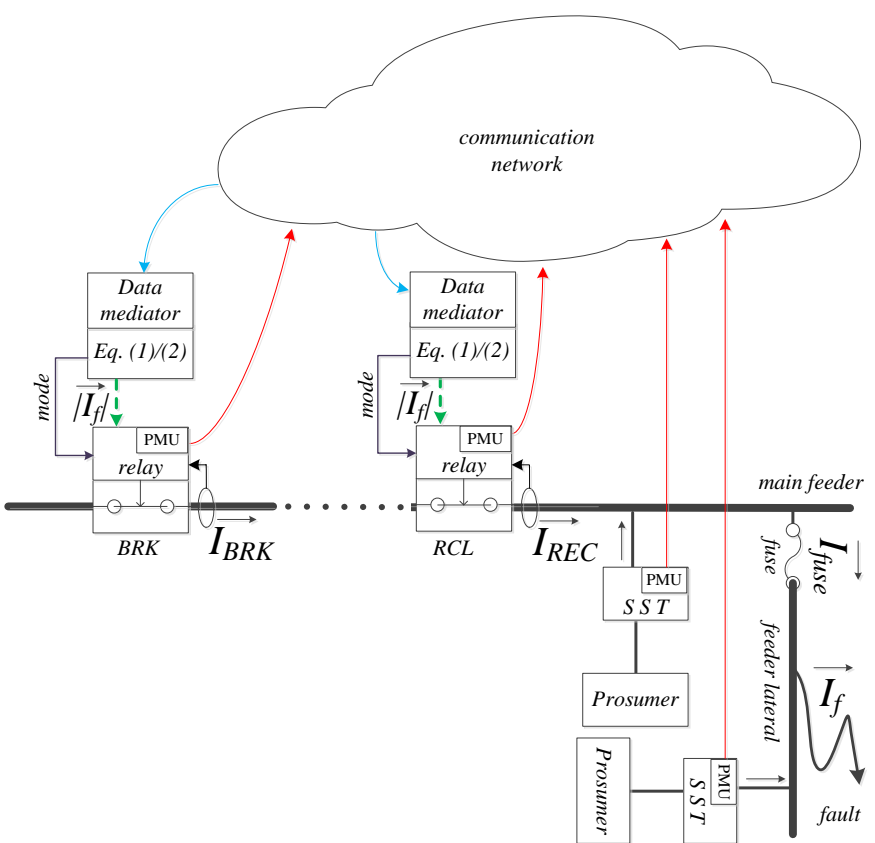

Fig. 9. The proposed PMU-assisted overcurrent protection scheme.

However in special cases where the lateral feeds a noticeable amount of SST installed rating, a similar study as the one shown in Fig. 8 may be performed to analyze recloserfuse coordination. Using the fault analysis method, introduced in [10] for SST-dominated distribution feeders, the fuse trip time should be compared with that of the recloser for faults occurring at both the beginning and end of the lateral with the highest fault resistance, against which both the recloser and the fuse are supposed to trip. This is to see if the fuse-recloser coordination is preserved. The study should be performed for both coordination methods of fuse-saving and fuse-blowing. As Fig. 10 shows, while the recloser sees the actual fault current in the proposed scheme, the fuse may see either less current, which occurs when the prosumer clusters are mostly energy-generative at noon time, or more current, which happens when the prosumer clusters are mostly energyconsuming at night time. Hence:

- At night time, the coordination between the recloser fast operation, used for the fuse-saving method, and the fuse might get hindered. In this case, the time-dial of the recloser curve should be reduced so that the designed time margin is achieved.

- At noon time, the coordination between the recloser slow operation, used for the fuse-blowing method, and the fuse might get hindered. In this case, the time-dial of the recloser curve and also the upstream breaker relay curve should be increased so that the designed time margin is achieved.

Note that the abovementioned adjustments are needed to the recloser and breaker curves because the fuse time-current characteristic is not adjustable.

Finally note that two different approaches can be taken to implement the abovementioned procedure for adjusting the curves. The first approach is to determine the adjustments based on the extreme conditions, i.e. assuming all prosumer clusters to be energy-consuming for adjusting the fast curve and assuming all clusters to be energy-generative for adjusting the slow curve. This approach results in conservative curves; however, it does not add any further requirement on the utilized ICT infrastructure. The second approach is to adjust the curves in real-time, which requires fault analysis studies to execute according to the real-time variations of the load/generation balance of the prosumer clusters. This approach results in more sensible curves; however, it requires a powerful computation unit to run fault analysis studies in real-time which, in turn, needs information on the real-time load/generation balance of the prosumer clusters. This information can be included as an analogue data within the PMU data frames sent by the SSTs, imposing higher data transfer rates on the utilized ICT infrastructure.

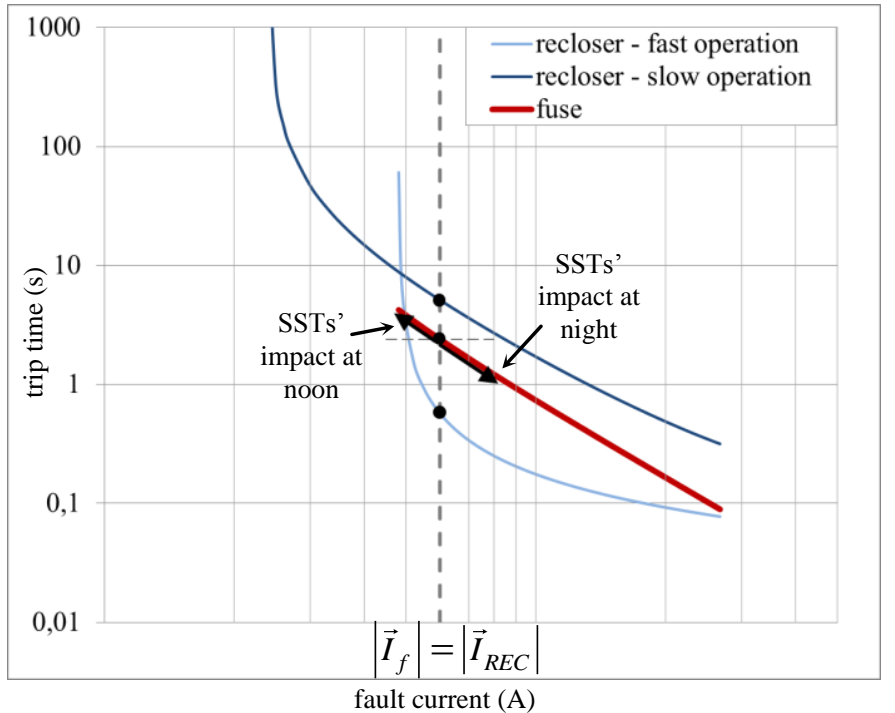

Fig. 10. Impact of SSTs on recloser-fuse coordination.

\section{B. Back-Up Scheme}

As explained in the previous section, the proposed overcurrent scheme utilizes the PMU data from SSTs and relays to compute the actual fault current. However there might be circumstances where a PMU malfunctions due to an error in phasor computation or poor time quality. These issues are detectable by the data mediator from bits $14-15$ and bits 06-08 of the STAT word of the PMU data frame, respectively [35].

Also, as the proposed scheme relies on the communication network to transfer the PMU data with minimal latency, the data mediator uses the GPS time clock, preliminarily installed for the relay PMU, to detect if the received PMU data frames are delayed. Note that since the proposed scheme has to run in hard real-time, the latency cannot be more than a cycle. Otherwise, the PMU data is considered to be invalid.

Upon the abovementioned detections, the proposed scheme takes the following remedies:

- If the invalid PMU data was sent from a SST, the scheme ignores the invalid data frame but it still computes (1)/(2) and sends $\left|\vec{I}_{f}\right|$ to the relay. This is because even though PMU data of one or a few SSTs are missing, (1)/(2) still 
provides a better estimate of $\left|\vec{I}_{f}\right|$ than the local current, e.g. $\left|\vec{I}_{B R K}\right| / 3\left|\vec{I}_{B R K}^{0}\right|$. Note that, in worst case, when PMU data of all SSTs are invalid, (1) computes $\left|\vec{I}_{f}^{a}\right|=\left|\vec{I}_{\text {relay }}^{a}\right|$.

- If the invalid PMU data was sent from a relay, the scheme changes its mode of operation and asks the relay, through the mode signal, to operate based on the local current, i.e. the relay will have its traditional performance, playing role of a back-up protection scheme. Although this paper is not intended to explain the implementation details, it's worth noting that the proposed scheme feeds $\left|\vec{I}_{f}\right|$, i.e. the RMS of the fault current, into the relay. Whereas, in the traditional operation, the relay inputs the instantaneous waveform of the current from which the current RMS is computed. Hence, the relay should treat these two inputs differently.

\section{Implementation and Test Results}

The proposed overcurrent protection scheme has been applied on the breaker relay and the recloser of the benchmark system through the hardware-in-the-loop setup shown in Fig 11. As indicated in the figure, the instantaneous waveforms of the currents of SSTs and relays are fed to the low-level inputs of the PMUs through the analogue output ports of the OPAL-RT simulator. The PMUs used in this setup are SEL-421 from Schweitzer Engineering Laboratories. Note that for the purpose of this study, the SEL-421 PMU functions are used to represent the assumed embedded PMU functionalities within SSTs and feeder protective relays. The PMU data are then streamed to the communication network over UDP/IP to a Compact Reconfigurable IO system (cRIO) from National Instruments Corporation, programmed with LabVIEW graphical programming tools to perform data time-alignment, data parsing and also phasor calculation of $\left|\vec{I}_{f}\right|$. The computed $\left|\vec{I}_{f}\right|$ is then sent back to the relay models through the analogue input of the OPAL-RT simulator.

Fig. 12 shows the trip time variation of the breaker ground relay while the proposed overcurrent scheme is applied. As the figure shows, unlike Fig. 6, the trip time curves are now flat, following the trip times of the original design for different load/generation balance of the local prosumers. Fig. 13 shows the trip time difference between the ground relays of the breaker and the recloser of the benchmark system while the proposed overcurrent scheme is applied. As the figure shows, unlike Fig. 8, the trip time difference curves are now flat and are all higher than the time margin of the original design for different load/generation balance of the local prosumers.

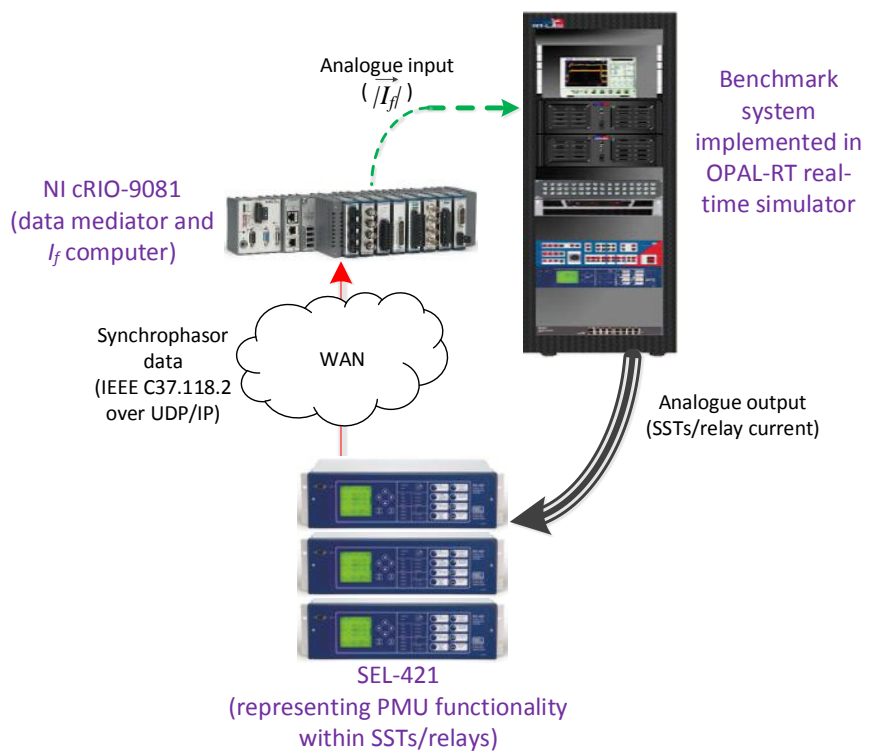

Fig. 11. Hardware-in-the-loop setup for assessing the performance of the proposed overcurrent scheme.

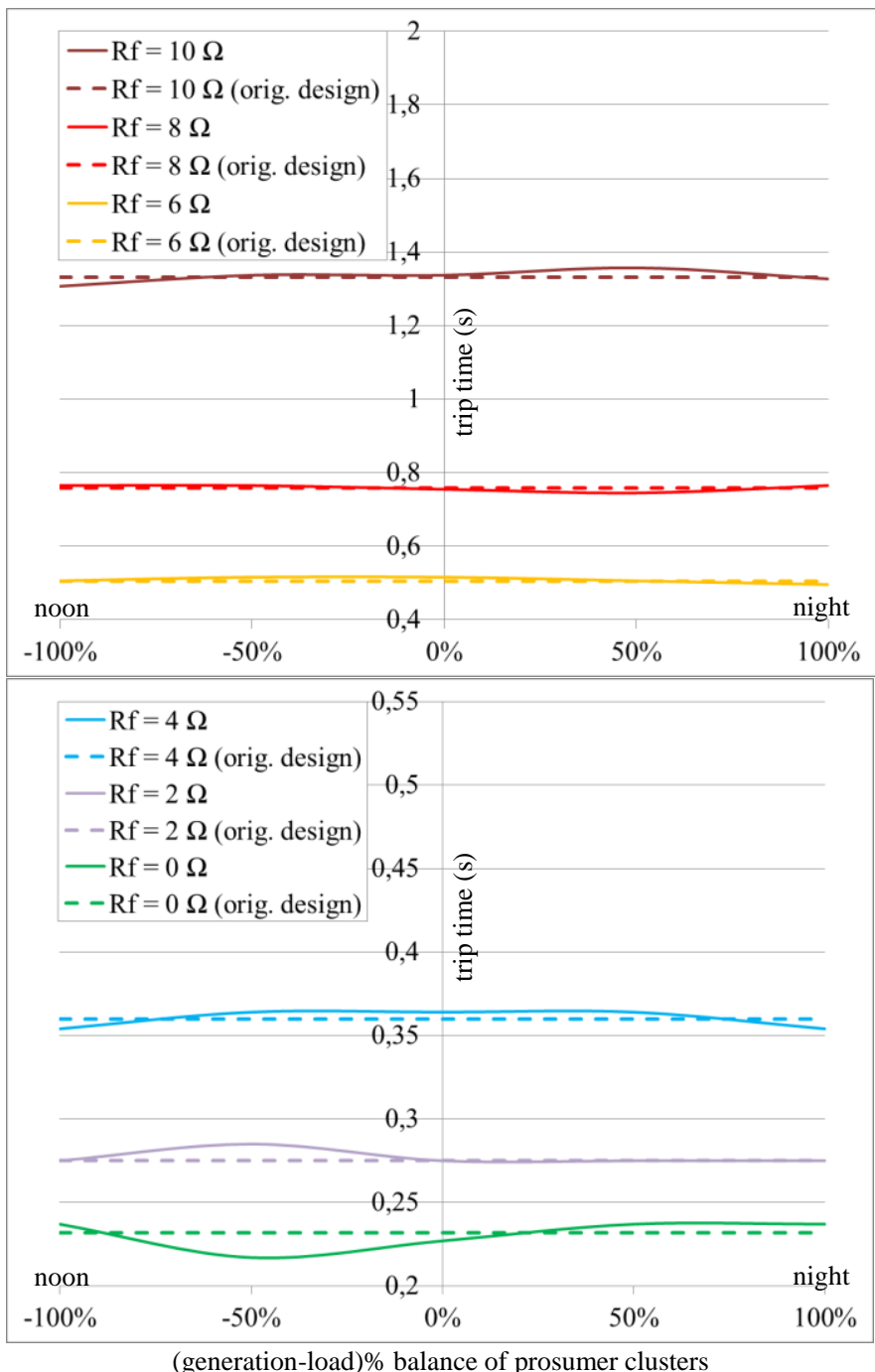

Fig. 12. Trip time of the breaker ground relay in the benchmark system while the proposed scheme is applied. The fault is line-to-ground at node 2 . 
Note that the time-current curves of both the breaker and the recloser are manipulated to response $60 \mathrm{~ms}$ faster to compensate for the delays caused by sampling window, simulator output D/A conversion, PMU processing, communication system I/O, data time-alignment and D/A conversion in the cRIO, and simulator input A/D conversion. It is worth mentioning that the overall delay of $60 \mathrm{~ms}$ is specific to the hardware-in-the-loop setup used in this study. As the delay is initiated by components of the ICT infrastructure (i.e. PMUs, data mediators, network switches, etc.), it needs to be quantified for every ICT infrastructure through proper analyses.

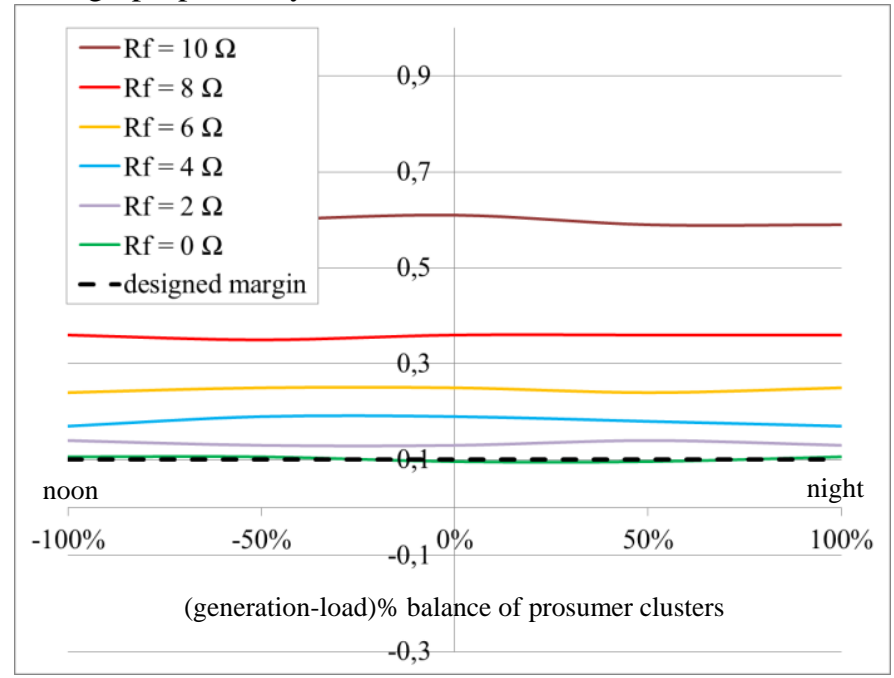

(a) fault occurs at node 1

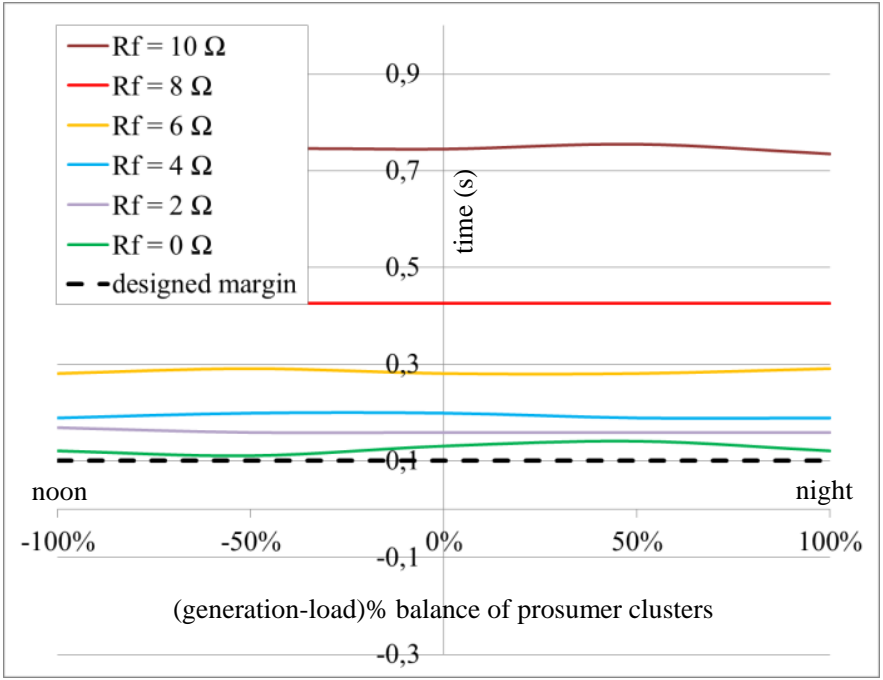

(b) fault occurs at node 2

Fig. 13. Trip time difference between the ground relays of the breaker and the recloser of the benchmark system while the proposed scheme is applied.

\section{Required ICT Infrastructure}

As described before, the proposed overcurrent scheme utilizes the in-use ICT backbone, employed for control of SST-dominated distribution systems [28]. However, it is important to investigate what requirements the proposed scheme imposes on the communication network.

Table I lists the bytes included in each PMU data frame streamed by SSTs and relays to the communication network. As the table shows, each PMU data frame consists of 34 bytes. Furthermore, the communication media, i.e. UDP/IP, adds 28 bytes to each PMU data frame. Assuming a reporting rate of 60 frames per second, each PMU loads the communication network at $(34+28) \times 60 \times 8=29760 \mathrm{bps}$. As indicated in Fig. 9, the most demanding information exchange is the transfer of the PMU data of all SSTs to the data mediator of the breaker relay at the substation. Hence, the communication link reaching the breaker is the one accommodating the heaviest traffic; therefore, it determines the maximum data transfer rate that the communication network should support. Assuming that the distribution system feeds 300 SSTs, i.e. 100 SSTs per phase, the communication network should be able to accommodate a transfer rate of 300 $\times 29760 \approx 9$ Mbps.

As the proposed scheme requires the PMU data to compute $\left|\vec{I}_{f}\right|$, any delay in the PMU data transfer directly delays the relay trip time. Hence, the transfer time limit of 3 ms, proposed by the IEC 61850-5 Standard for the data transfer of trip signals, has to be considered as the transfer time limit of the PMU data [36].

Considering the maximum transfer rate of $9 \mathrm{Mbps}$ and the maximum transfer time of $3 \mathrm{~ms}$, communication technologies such as fiber-optic, LTE, and HiperLAN can satisfy the imposed requirements $[37,38]$.

TABLE I

PMU DATA FRAME STREAMED BY SST/RELAY

\begin{tabular}{|c|c|c|}
\hline Field & Description & 苛苞 \\
\hline SYNC & $\begin{array}{l}\text { Sync byte followed by frame type and version } \\
\text { number. }\end{array}$ & 2 \\
\hline FRAMESIZE & Number of bytes in frame. & 2 \\
\hline IDCODE & Stream source ID number. & 2 \\
\hline SOC & SOC time stamp. & 4 \\
\hline FRACSEC & Fraction of second and time quality. & 4 \\
\hline STAT & Bit-mapped flags. & 2 \\
\hline PHASORS & Phasor of phase current in floating-point format. & 8 \\
\hline FREQ & Frequency in floating-point format. & 4 \\
\hline DFREQ & ROCOF in floating-point format. & 4 \\
\hline $\mathrm{CHK}$ & CRC-CCITT & 2 \\
\hline \multicolumn{2}{|r|}{ Total number of bytes } & 34 \\
\hline
\end{tabular}

\section{CONCLUSION}

The paper showed that the fault current profile on a SSTdominated distribution system can be noticeably different from that of a conventional system. It is shown that SSTs' contribution to the fault current impact the operation and coordination of overcurrent relays.

Also, the paper proposed an enhanced overcurrent protection scheme which exploits the embedded PMU functionality within relays and SSTs and also utilizes the ICT backbone of SST-dominated distribution systems to manage SST's impact so that the relays operate properly with their original reach and speed, and also stay coordinated with each other. The simulation-based test results, performed in a hardware-in-the-loop setup, indicated the effectiveness of the proposed scheme. Utilizing the in-use protective hardware (relays and fuses) and also the in-use ICT backbone, 
employed preliminarily for control of SSTs, makes the proposed scheme economically affordable.

\section{REFERENCES}

[1] T. Gonen, Electric Power Distribution System Engineering, $3^{\text {rd }}$ edition, CRC Press, 2014.

[2] J. Arai, K. Koyanagi, R. Yokoyama, "Power electronics and its applications to renewable energy in Japan", IEEE Circuits and Systems Magazine, vol. 8, no. 3, 2008, pp. $52-56$.

[3] F. Bouhafs, M. Mackay, M. Merabti, "Links to the Future: Communication Requirements and Challenges in the Smart Grid", IEEE Power and Energy Magazine, vol. 10, no. 1, 2012, pp. 24 - 32.

[4] B. Kroposki, N. Hatziargyriou, "Making microgrids work", IEEE Power and Energy Magazine, vol. 6, no. 3, 2008, pp. 40 - 53.

[5] T. Zhao, J. Zeng, S. Bhattacharya, M. E. Baran, "An average model of solid state transformer for dynamic system simulation", IEEE PES General Meeting, 26-30 July 2009, pp. 1-8.

[6] L. Yang, T. Zhao, J. Wang, A.Q. Huang, "Design and analysis of a $270 \mathrm{~kW}$ five-level DC/DC converter for solid state transformer using 10kV SiC Power Devices," IEEE 2007 Power Electronics Specialists Conference, 2007, pp. 245-251.

[7] E.R.Jr. Ronan, S.D. Sudhoff, S.F. Glover, D.L. Galloway, "Application of power electronics to the distribution transformer," IEEE Applied Power Electronics Conference, 2000, vol.2, pp. 861-867.

[8] T. Guillod; F. Krismer; J. Kolar, "Protection of MV Converters in the Grid: The Case of MV/LV Solid-State Transformers," IEEE Journal of Emerging and Selected Topics in Power Electronics, Early Access Available at http://ieeexplore.ieee.org/

[9] M.L. Crow, B. McMillin, W. Wang, S. Bhattacharyya, "Intelligent Energy Management of the FREEDM System," IEEE PES General Meeting, 25-29 July 2010, pp. 1-4.

[10] H Hooshyar, M.E. Baran, "Fault analysis on distribution feeders employing Solid State Transformers," IEEE PES GM, 2014.

[11] R.A. Walling, R. Saint, R.C. Dugan, J. Burke, "Summary of distributed resources impact on power delivery systems", IEEE Transactions on Power Delivery, vol. 23, no. 3, July 2008, pp. 1636 - 1644.

[12] A. Carta, N. Locci, C. Muscas, "A PMU for the measurement of synchronized harmonic phasors in three-phase distribution networks," IEEE Trans. on Instrumentation and Meas., vol. 58, no. 10, pp. 37233730, Oct. 2009

[13] J. Liu, J. Tang, F. Ponci, A. Monti, C. Muscas, P. A. Pegoraro, "Tradeoffs in PMU deployment for state estimation in active distribution grids," IEEE Transactions on Smart Grid, vol. 3, no. 2, pp. 915-924, June 2012

[14] L. Zhan, Y. Liu, J. Culliss, J. Zhao and Y. Liu, "Dynamic single-phase synchronized phase and frequency estimation at the distribution level," IEEE Trans. on Smart Grid, vol. 6, no. 4, pp. 2013-2022, July 2015.

[15] J. Ren, S. S. Venkata and E. Sortomme, "An accurate synchrophasor based fault location method for emerging distribution systems," IEEE Transactions on Power Delivery, vol. 29, no. 1, pp. 297-298, Feb. 2014.

[16] F. Casali, "Field experience of phasors measurement in a distribution network with increased level of LV-connected PV," $22^{\text {nd }}$ Int. Conf. and Exhibition on Electricity Distribution (CIRED), Stockholm, 2013.

[17] A. von Meier, D. Culler, A. McEachern, R. Arghandeh, "Microsynchrophasors for distribution systems," IEEE PES ISGT, Washington, DC, 2014.

[18] B. Dickerson, "Precision timing in the power industry: how and why we use it," [Online]. Available: http://www.arbiter.com/news/technology.php?id=4

[19] D. Dujic, C. Zhao, A. Mester, J. K. Steinke, M. Weiss, S. L. Schmid, T. Chaudhuri, and P. Stefanutti, "Power electronic traction transformer: Low voltage prototype," IEEE Trans. on Power Electronics, vol. 28, no. 12, pp. 5522-5534, Dec. 2013.

[20] P. Drabek, Z. Peroutka, M. Pittermann, and M. Cedl, "New configuration of traction converter with medium frequency transformer using matrix converters," IEEE Trans. on Industrial Electronics, vol. 58, no. 11, pp. 5041-5048, Nov. 2011.

[21] M. Glinka and R. Marquardt, "A new AC/AC multilevel converter family," IEEE Trans. on Industrial Electronics, vol. 52, no. 3, pp. 662669, Jun. 2005.
[22] G. Brando, A. Dannier, A. D. Pizzo, and R. Rizzo, "A high performance control technique of power electronic transformers in medium voltage grid-connected PV plants," Proc. 19th ICEM, Sep. 2010, pp. 1-6.

[23] X. She, A. Q. Huang, F. Wang, and R. Burgos, "Wind energy system with integrated active power transfer, reactive power compensation, and voltage conversion functions," IEEE Trans. on Industrial Electronics, vol. 60, no. 10, pp. 4512-4524, Oct. 2013.

[24] A. Q. Huang, M. L. Crow, G. T. Heydt, J. P. Zheng, and S. J. Dale, "The future renewable electric energy delivery and management system: The energy Internet," Proc. IEEE, vol. 99, no. 1, pp. 133-148, Jan. 2011.

[25] G. G. Karady and Xing Liu, "Fault management and protection of FREEDM systems," IEEE PES General Meeting, Minneapolis, MN, 2010, pp. 1-4.

[26] P. Tatcho, L. Hui, J. Yu, Q. Li, "A Novel hierarchical section protection based on the solid state transformer for the Future Renewable Electric Energy Delivery and Management (FREEDM) System," IEEE Transactions on Smart Grids, vol.4, no.2, June 2013, pp. 1096 - 1104.

[27] P. Tatcho, Y. Jiang, H. Li, "A novel line section protection for the FREEDM system based on the solid state transformer," IEEE PES General Meeting, 2011.

[28] X. Lu, W. Wang, A. Juneja, A. Dean, "Talk to transformers: An empirical study of device comm. for the FREEDM system," IEEE SmartGridComm, 2011.

[29] X. She, A. Huang, "Review of solid state transformer in the distribution system: from components to field application," IEEE Energy Conversion Congress and Exposition (ECCE), 2012, pp. 4077-4084.

[30] X. She, A. Q. Huang and R. Burgos, "Review of solid-state transformer technologies and their application in power distribution systems," IEEE Journal of Emerging and Selected Topics in Power Electronics, vol. 1, no. 3, pp. 186-198, Sept. 2013.

[31] R. J. G. Montoya, A. Mallela and J. C. Balda, "An evaluation of selected solid-state transformer topologies for electric distribution systems," 2015 IEEE Applied Power Electronics Conference and Exposition (APEC), Charlotte, NC, 2015, pp. 1022-1029.

[32] V. Ramachandran, A. Kuvar, U. Singh, S. Bhattacharya, M. Baran, "A system level study employing improved solid state transformer average models with renewable energy integration," IEEE PES General Meeting, 2014.

[33] IEEE Recommended Practice for Utility Interface of Photovoltaic (PV) Systems, IEEE 929, 2000.

[34] Model Available on the Website of ECEE Department at the University of Colorado at Boulder [Online]. Available: http://ecee.colorado.edu/ ecen2060/matlab.html

[35] IEEE Standard for Synchrophasor Data Transfer for Power Systems, IEEE Std C37.118.2, 2011.

[36] Communication networks and systems for power utility automation Part 5: Communication requirements for functions and device models, IEC 61850-5, 2013.

[37] Architecture Design and Implementation, deliverable 3.2 of EU FP7IDE4L (ideal grid for all), RWTH Aachen University, Germany [Online]. Available: http://ide4l.eu/results/

[38] Universal Mobile Telecommunications System (UMTS); LTE; Requirements for Evolved UTRA (E-UTRA) and Evolved UTRAN (EUTRAN), ETSI Technical Report 125 913, v9.0.0, 2010. 